\title{
A novel through-the-snare technique for percutaneous endoscopic gastrojejunostomy tube placement
}
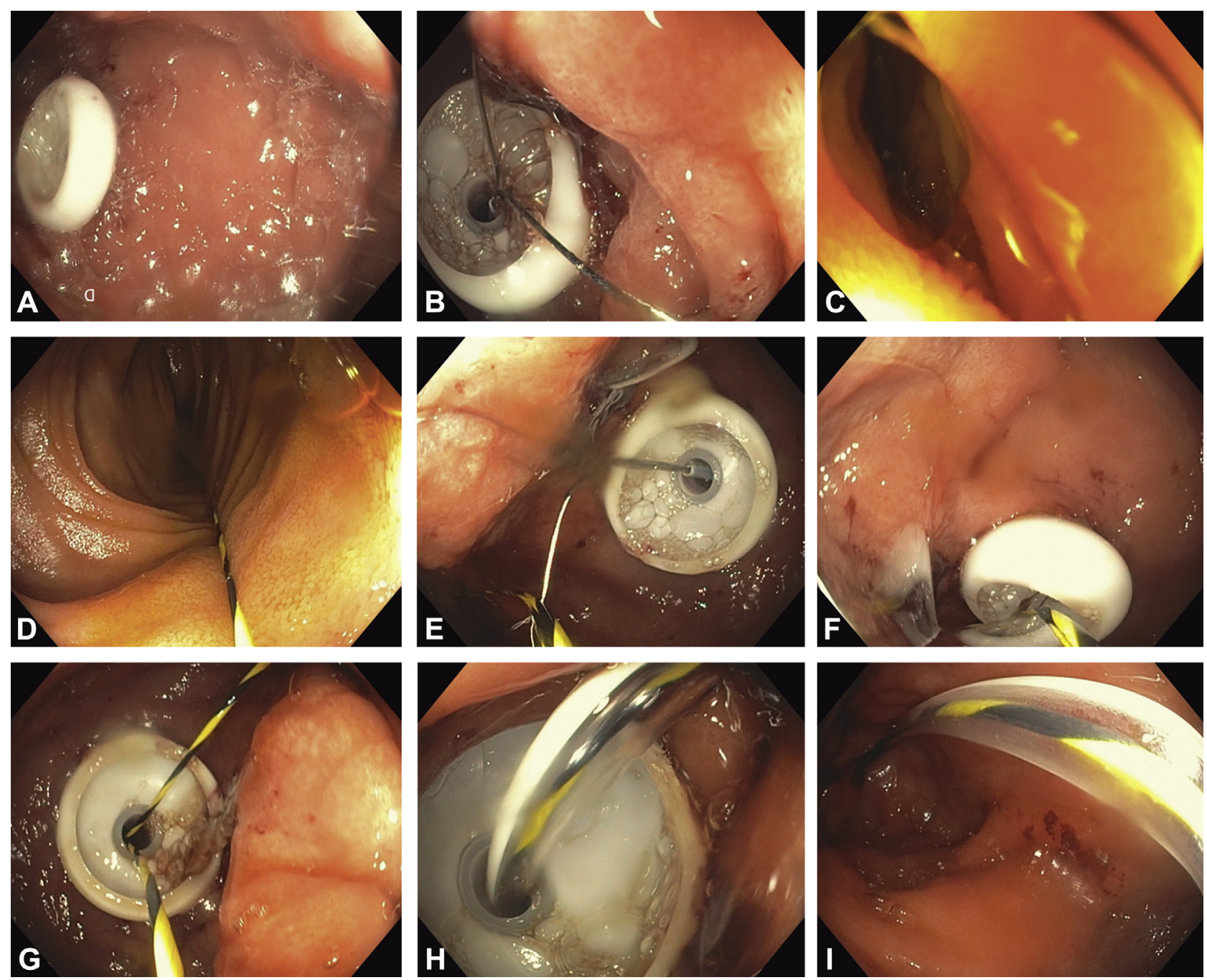

Figure 1. A, A 24F PEG tube is placed. B, A snare is opened through the previously placed PEG tube. C, The gastroscope is advanced through the open snare and into the small bowel. $\mathbf{D}$, A long guidewire is advanced through the working channel of the endoscope into the small bowel and is then exchanged as the endoscope is withdrawn. E, As the endoscope is removed, the guidewire is left through the open snare. F, The snare is closed and pulled through the PEG tube. G, The end of the guidewire not within the small bowel is pulled back to allow passage of the jejunal feeding tube into the small bowel. $\mathbf{H}$, The jejunal extension is advanced into the small bowel. I, Jejunal extension tubing is in place with no loop in stomach.

Percutaneous endoscopic gastrojejunostomy (PEG-J) tube placement is an increasingly in demand procedure, but due to technical difficulty and its time consuming nature, is often referred to surgeons and interventional radiologists. The most common procedural complications include loop formation within the stomach which causes retraction of either the guidewire or jejunal extension tubing out of the small bowel as well as displacement of the jejunal extension tubing out of the small bowel during withdrawal of the endoscope. Here we present a modified 
version of a through-the-snare technique for PEG-J placement, previously described in an article published in Gastrointestinal Endoscopy by Leichus et al, which decreases procedure length and may be easier to perform than the traditional methods (Video 1, available online at www.VideoGIE.org).

A 24F PEG tube was placed in the traditional fashion (Fig. 1A). Next, a snare was placed through the PEG tube and opened (Fig. 1B). The endoscope was advanced through the snare and a guidewire was placed into the small bowel (Fig. 1C). The endoscope was then exchanged and the wire left in place (Fig. 1D). As the endoscope was withdrawn, through the snare, the snare was closed and the wire brought out through the PEG tube (Figs. 1E and F). The end of the wire not within the small bowel was then pulled back to straighten the guidewire (Fig. 1G). The jejunal extension tube was then advanced over the guidewire (Figs. $1 \mathrm{H}$ and $\mathrm{I}$ ). The procedure duration was 18 minutes.
This method for PEG-J placement is technically simple and helps eliminate looping of the guidewire. Furthermore, it obviates the need for the use of a second endoscope as well as fluoroscopy, which may not be readily available at all centers.

\section{DISCLOSURE}

All authors disclosed no financial relationships relevant to this publication.

Gabriel D. Lang, MD, Daniel K. Mullady, MD, Vladimir M. Kushnir, MD, Washington University, Section of Gastroenterology, Saint Louis, Missouri, USA

Copyright (c) 2017 American Society for Gastrointestinal Endoscopy. Published by Elsevier Inc. This is an open access article under the CC BY-NC-ND license (http://creativecommons.org/licenses/by-nc-nd/4.0/).

http://dx.doi.org/10.1016/j.vgie.2017.04.005 